\title{
Synthesis of Ladder-Type Thienoacenes and Their Electronic and
}

\section{Optical Properties}

Tianyue Zheng, ${ }^{1}$ Zhengxu Cai, ${ }^{1}$ Rosina Ho-Wu, ${ }^{2}$ Sung Hei Yau, ${ }^{2}$ Valerii Shaparov, ${ }^{1}$ Theodore Goodson $\mathrm{III}^{2 *}$ and Luping $\mathrm{Yu}^{1 *}$

1. Department of Chemistry and the James Franck Institute, The University of Chicago, 929 E $57^{\text {th }}$ Street, Chicago, IL 60637

2. Department of Chemistry and Department of Macromolecular Science and Engineering, University of Michigan, Ann Arbor, Michigan 48109

Email: 1upingyu@uchicago.edu; tgoodson@umich.edu

Table of Contents

1. Figure S1 MALDI-TOF MS spectrum of FBT-11R ......................................... S2

2. Figure S2 Optimized geometry of FBT series molecules at DFT B3LYP/6-31G(d). The alkoxy side chains are replaced by methoxy groups.................................................. S2

3. Figure S3 HOMO and LUMO molecular orbital distribution of BDT-based thienoacene oligomers at DFT B3LYP/6-31G(d). The alkoxy side chains are replaced by methoxy groups. S3

4. Figure S4 Calculated HOMO/LUMO energy levels of nBDT oligomers using DFT at b3lyp/6-31g(d) (left) and Eg vs 1/(number of rings) plot (right) ............................... S4

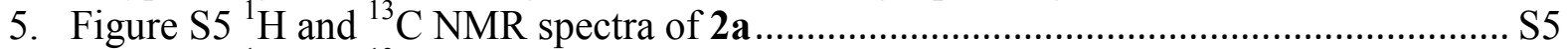

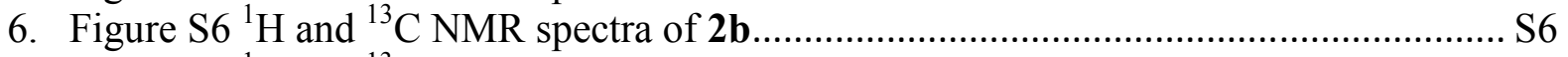

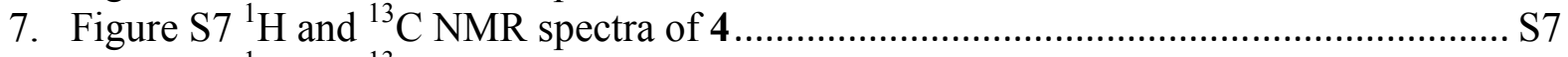

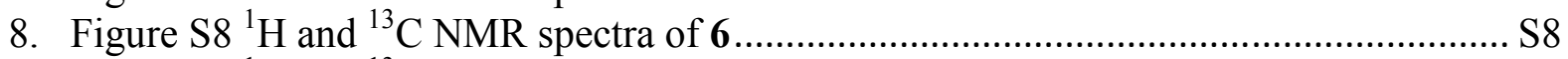

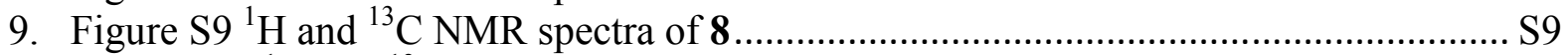

10. Figure $\mathrm{S} 10{ }^{1} \mathrm{H}$ and ${ }^{13} \mathrm{C}$ NMR spectra of FBT-11R............................................... S10

11. Figure $\mathrm{S} 11{ }^{1} \mathrm{H}$ and ${ }^{13} \mathrm{C}$ NMR spectra of FBT-15R ................................................ S 11

12. Figure $\mathrm{S} 12{ }^{1} \mathrm{H}$ and ${ }^{13} \mathrm{C}$ NMR spectra of FBT-21R............................................. S12

13. Figure S13 MALDI-TOF MS spectra of FBT-15R and FBT-21R.......................... S13 


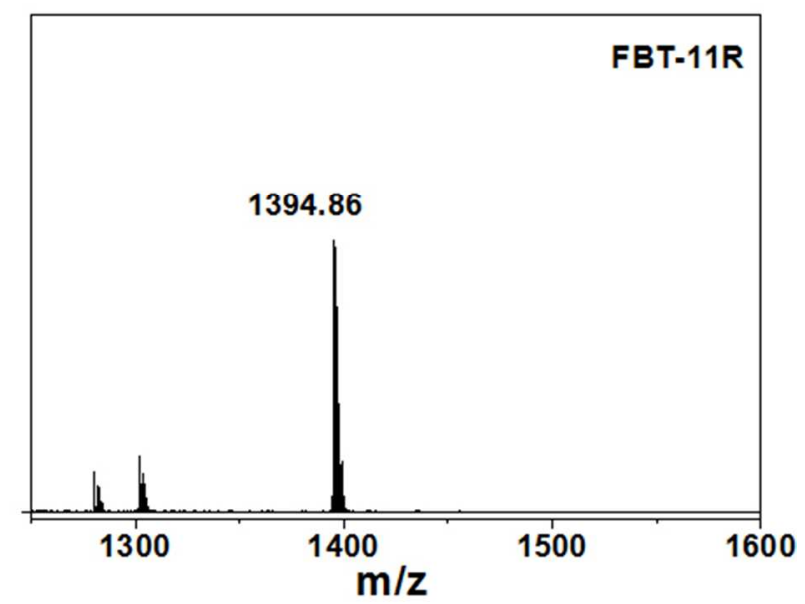

Figure S1 MALDI-TOF MS spectrum of FBT-11R.

$11 R$
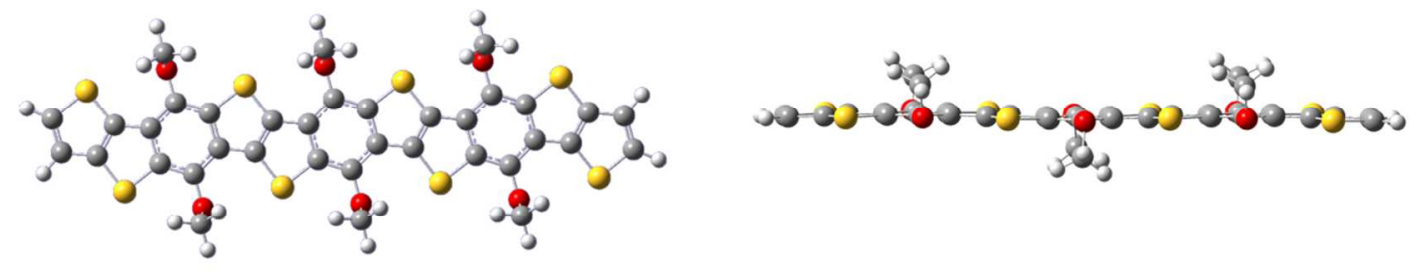

$15 R$
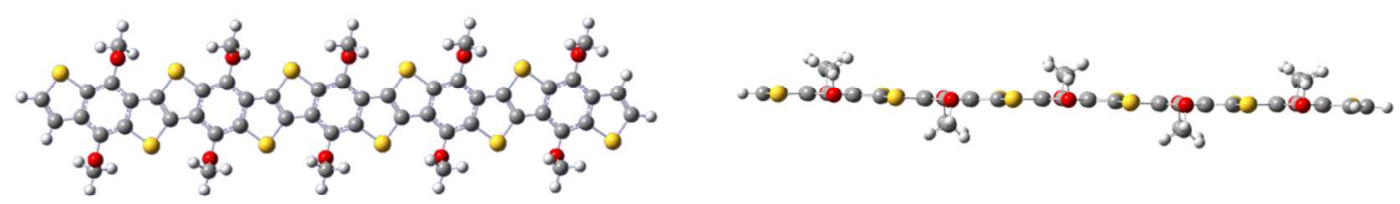

$21 R$
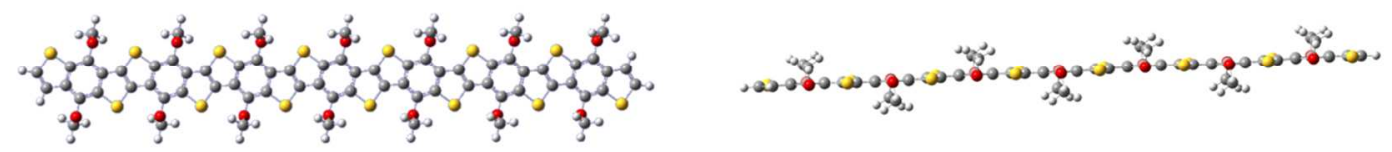

Figure S2 Optimized geometry of FBT series molecules at DFT B3LYP/6-31G(d). The alkoxy side chains are replaced by methoxy groups. 

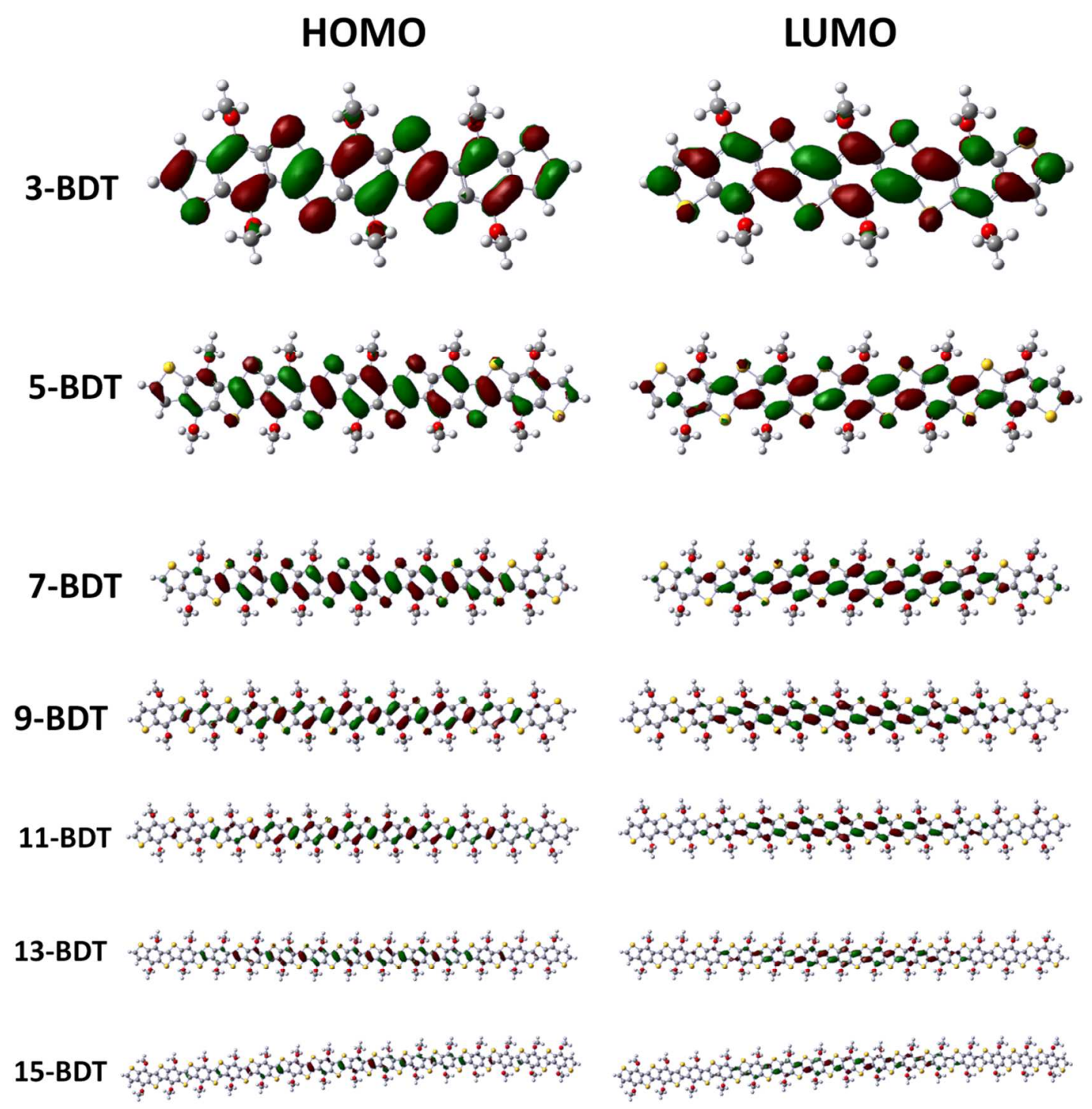

Figure S3 HOMO and LUMO molecular orbital distribution of BDT-based thienoacene oligomers at DFT B3LYP/6-31G(d). The alkoxy side chains are replaced by methoxy groups. 


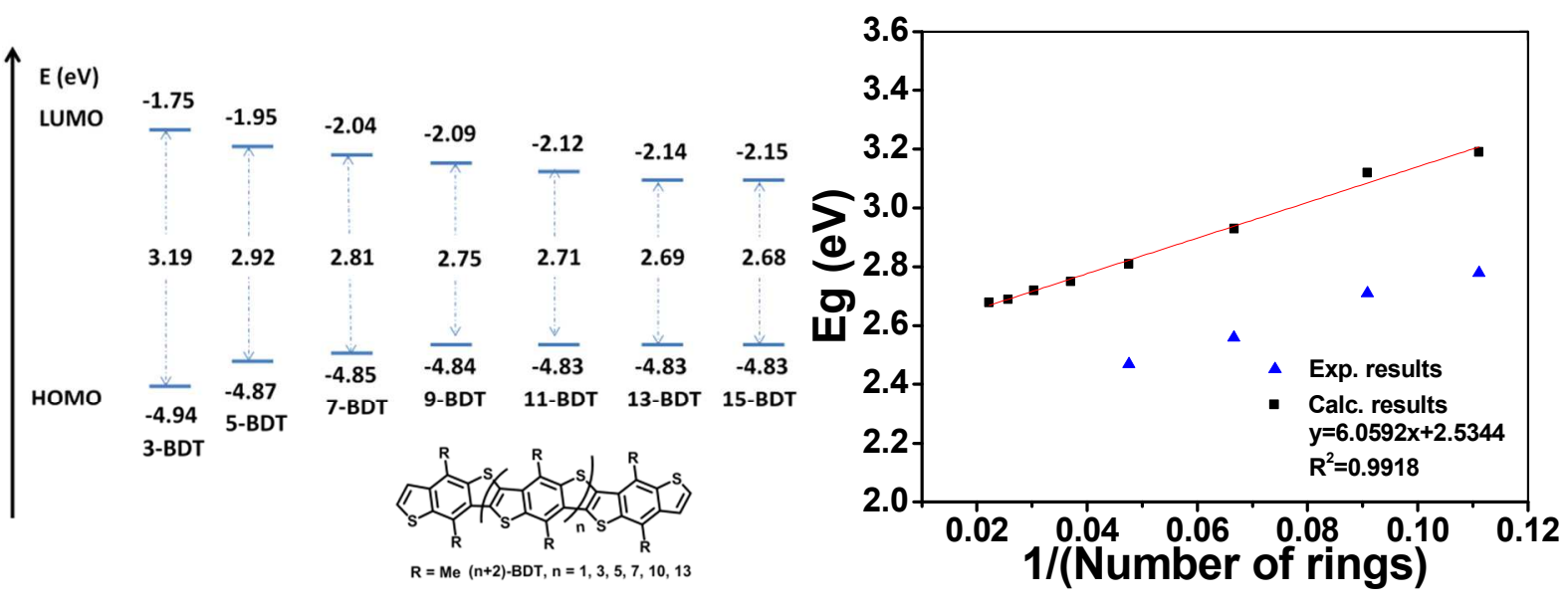

Figure S4 Calculated HOMO/LUMO energy levels of nBDT oligomers using DFT at b3lyp/6$31 \mathrm{~g}(\mathrm{~d})$ (left) and Eg vs 1/(number of rings) plot (right). 


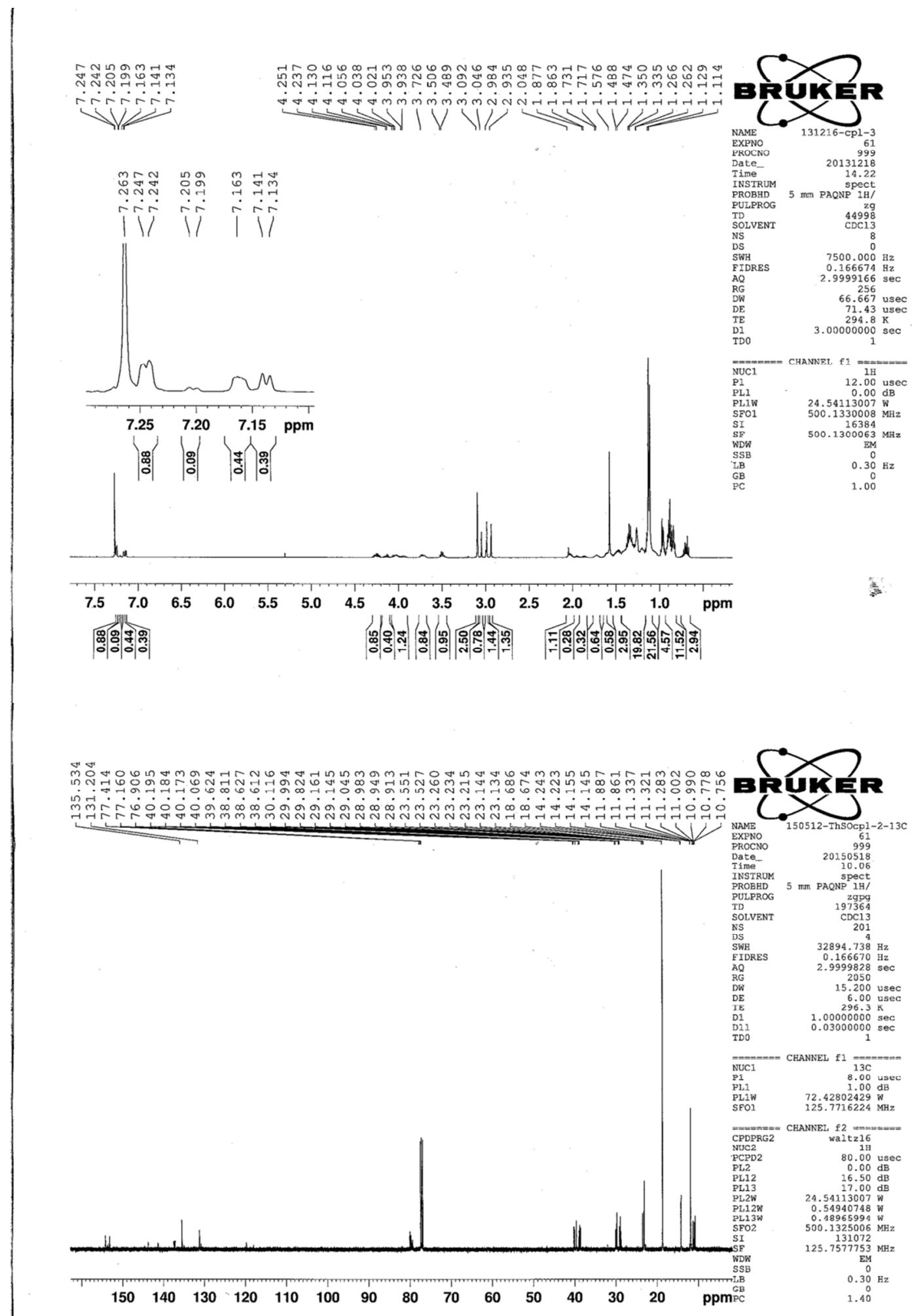

Figure $\mathrm{S} 5{ }^{1} \mathrm{H}$ and ${ }^{13} \mathrm{C}$ NMR spectra of $\mathbf{2 a}$ 

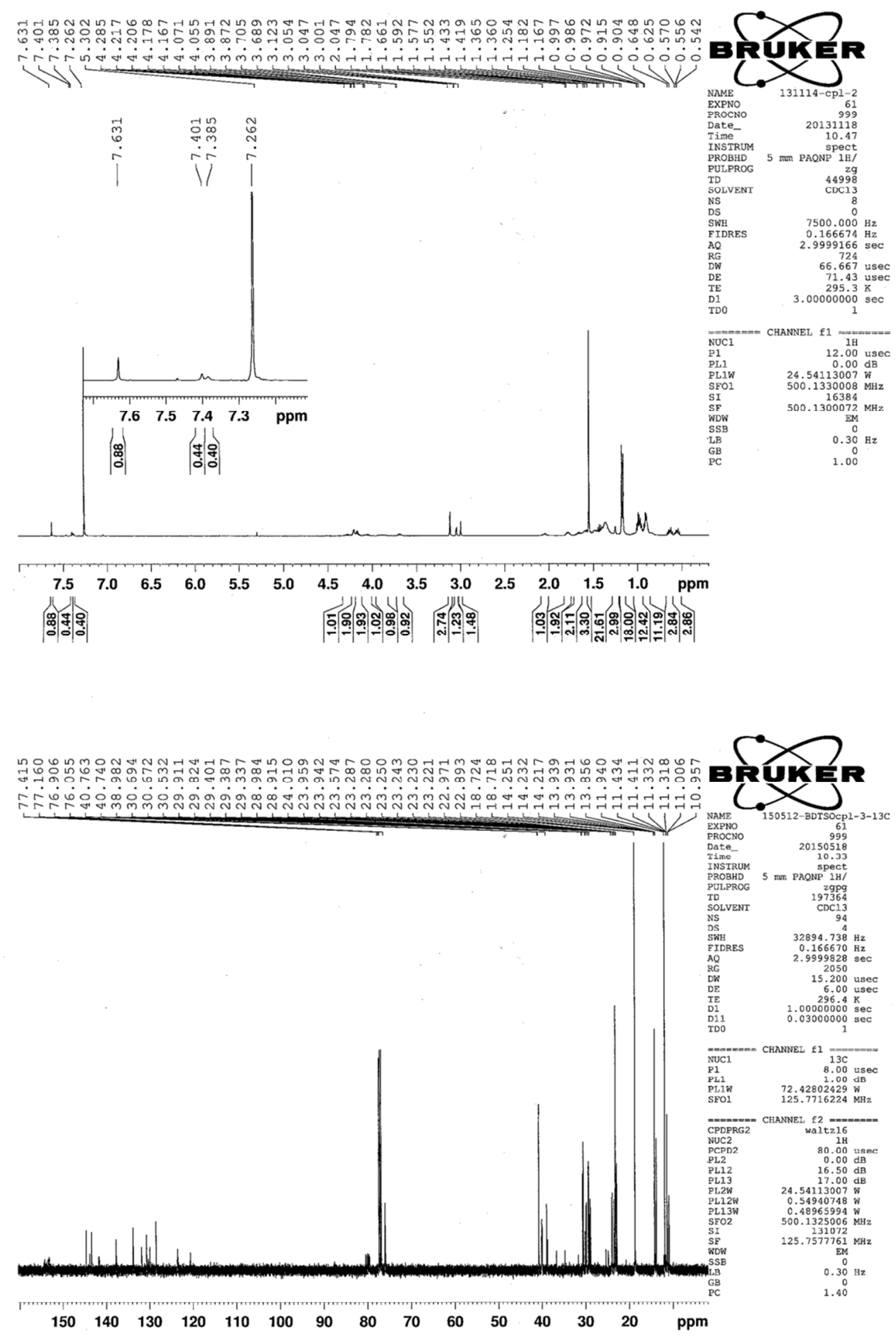

Figure $\mathrm{S} 6{ }^{1} \mathrm{H}$ and ${ }^{13} \mathrm{C}$ NMR spectra of $\mathbf{2 b}$ 

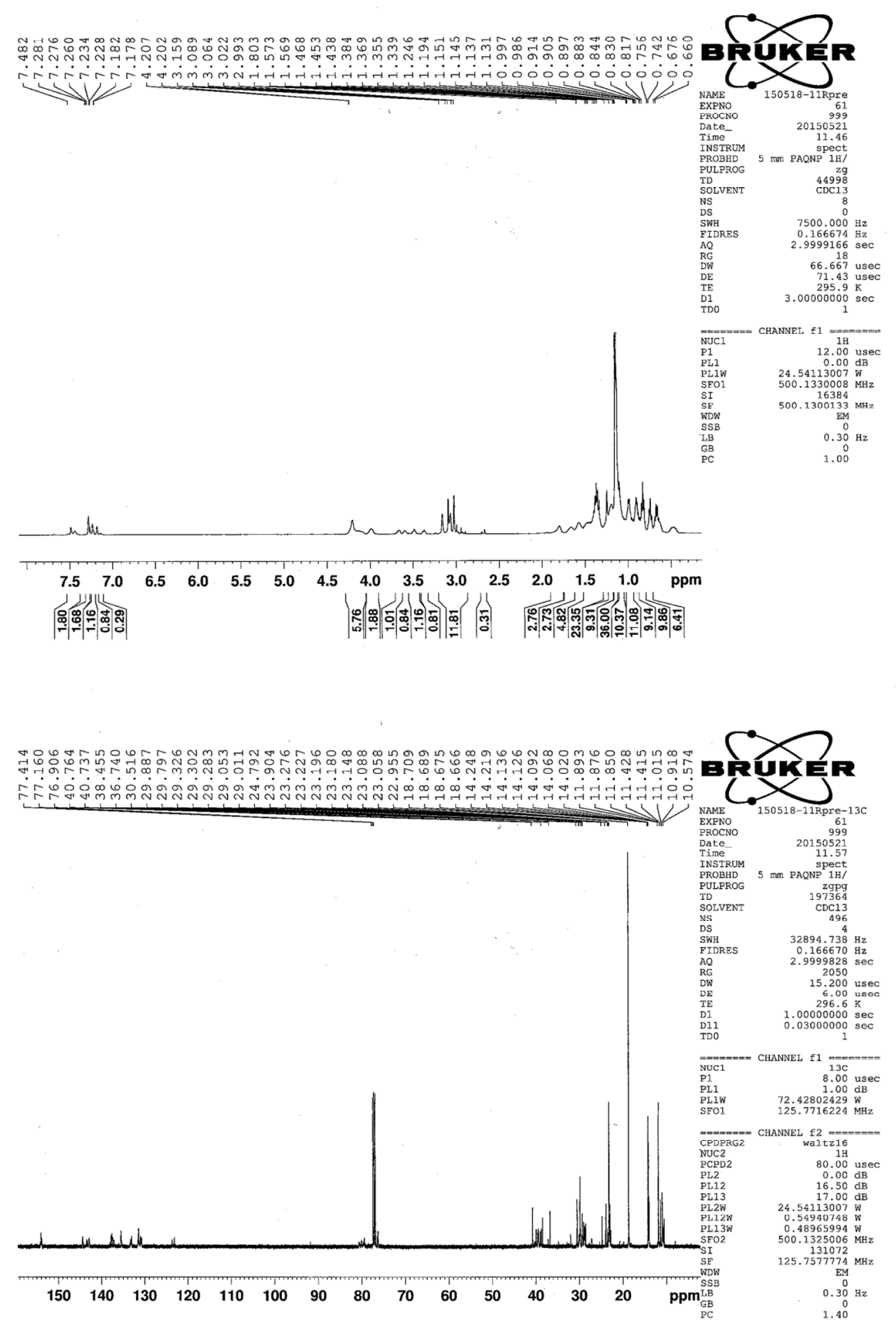

Figure $\mathrm{S} 7{ }^{1} \mathrm{H}$ and ${ }^{13} \mathrm{C}$ NMR spectra of 4 

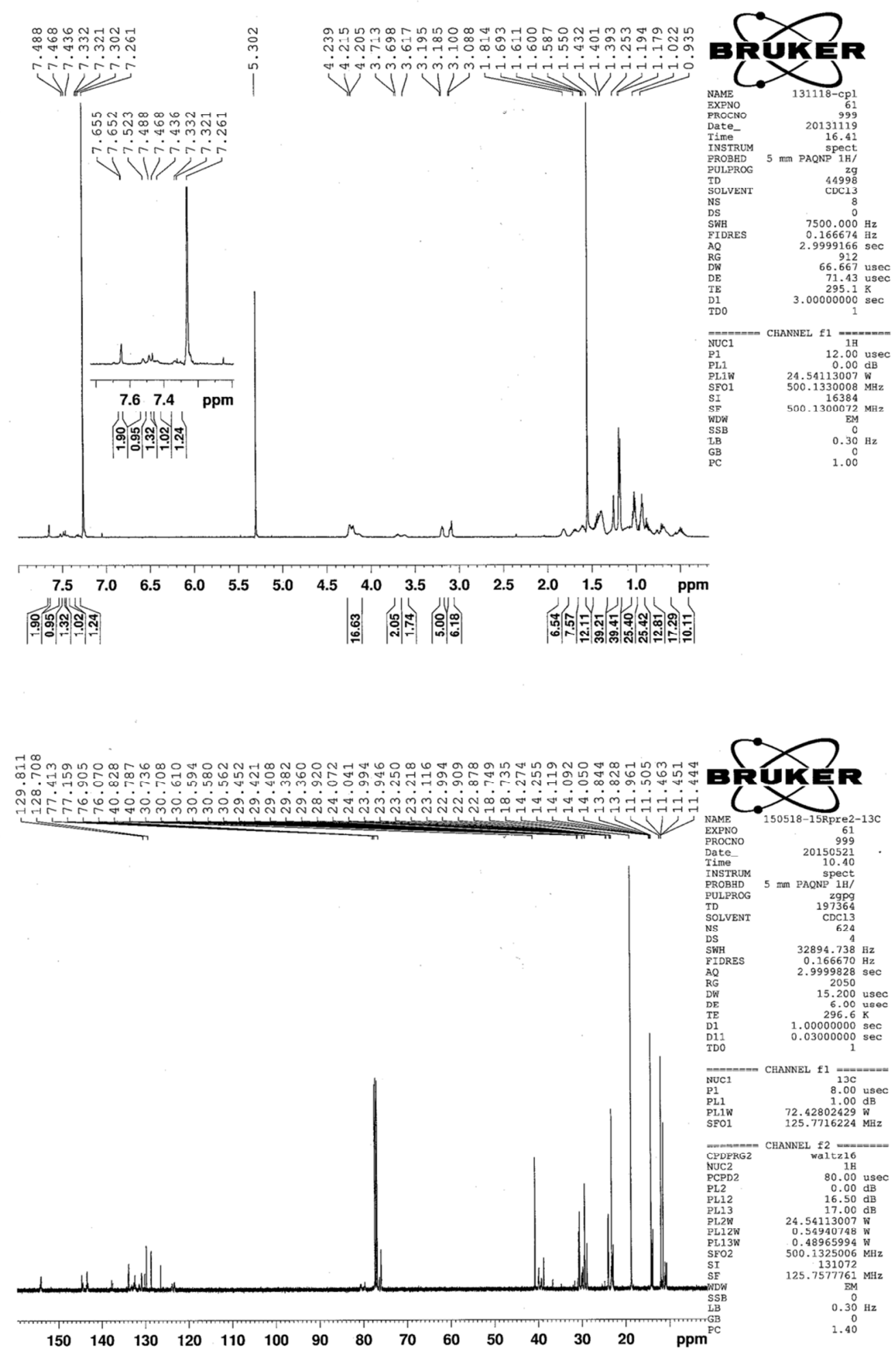

Figure S8 ${ }^{1} \mathrm{H}$ and ${ }^{13} \mathrm{C}$ NMR spectra of 6 

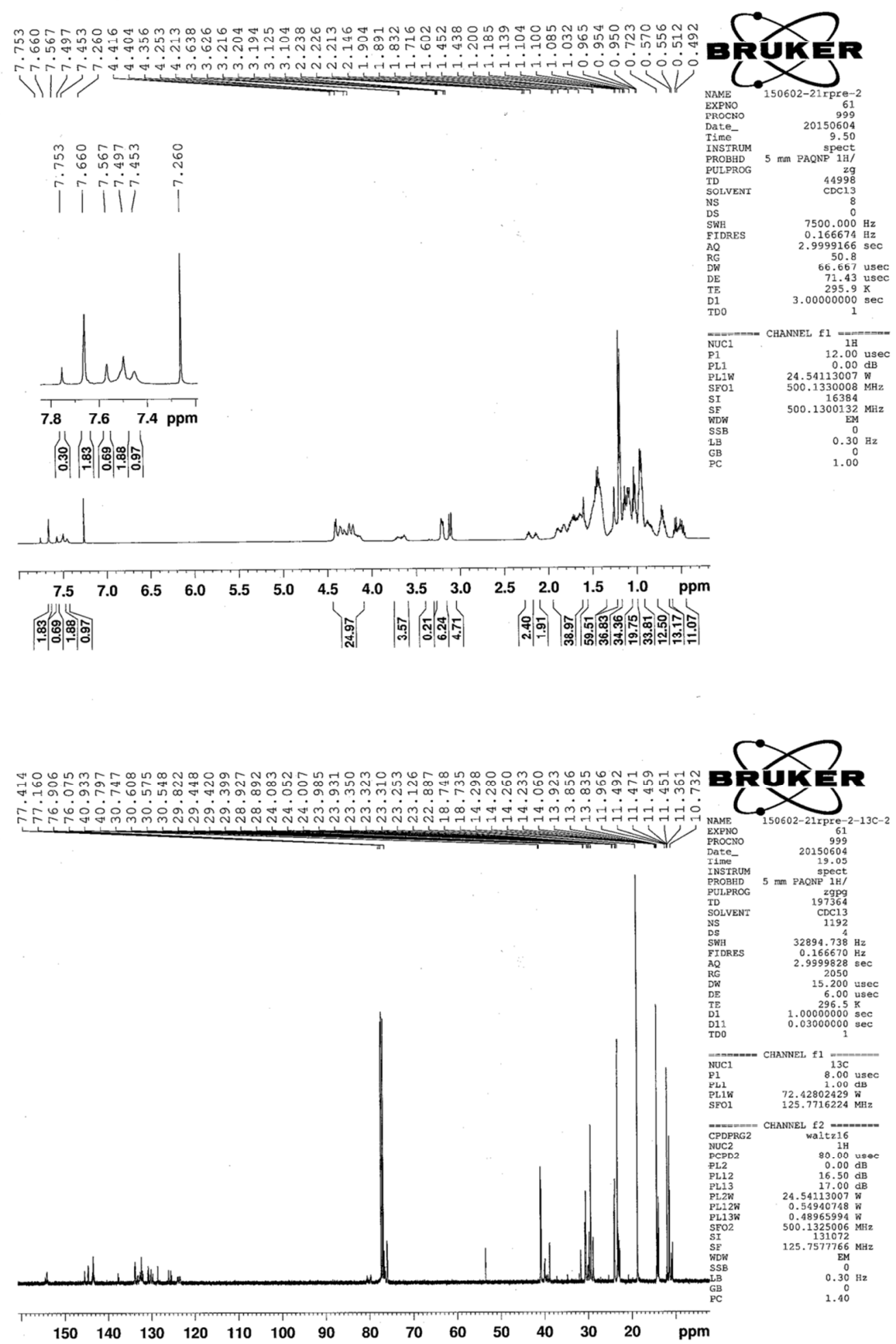

Figure S9 ${ }^{1} \mathrm{H}$ and ${ }^{13} \mathrm{C}$ NMR spectra of 8 


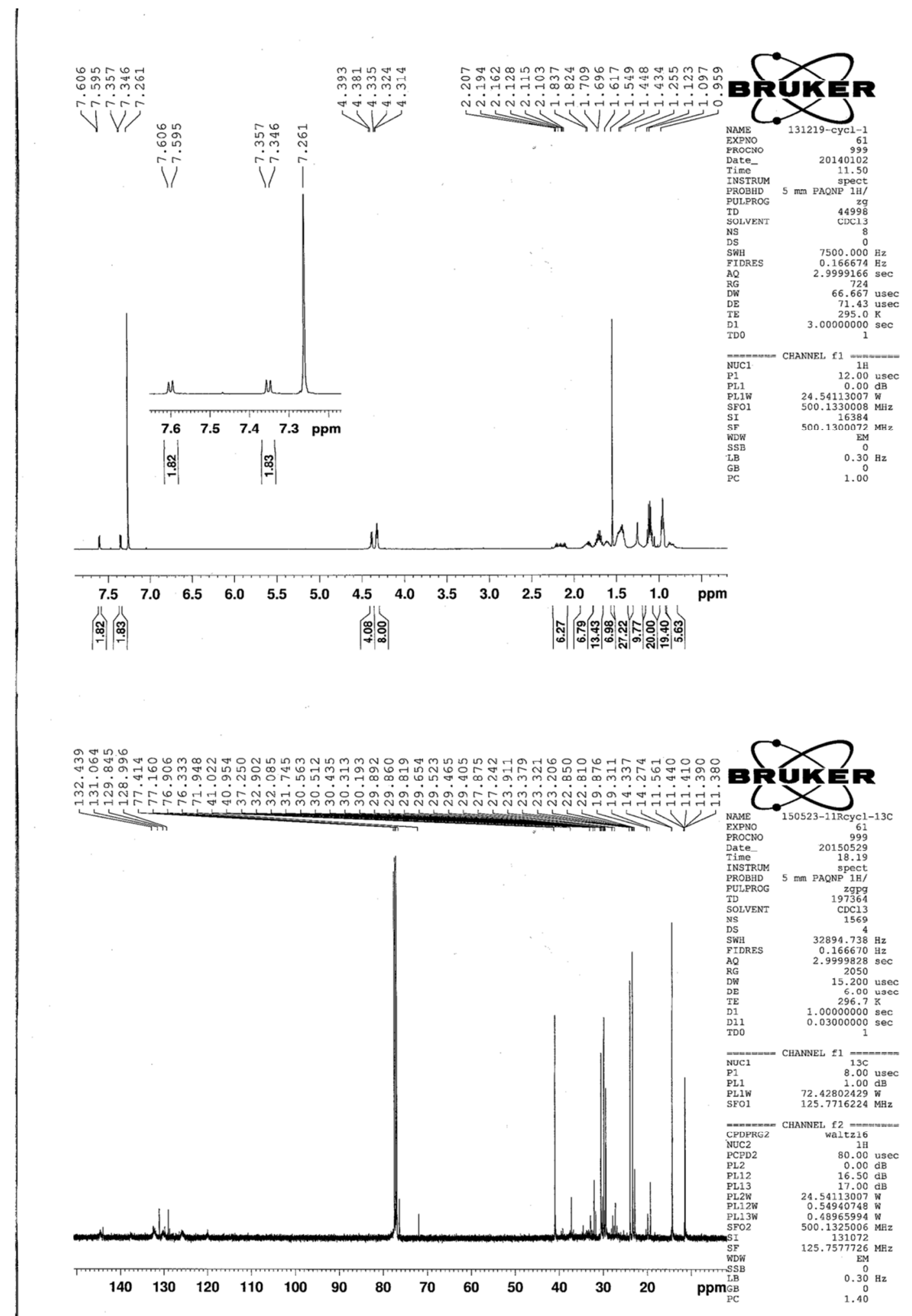

Figure S10 ${ }^{1} \mathrm{H}$ and ${ }^{13} \mathrm{C}$ NMR spectra of FBT-11R 


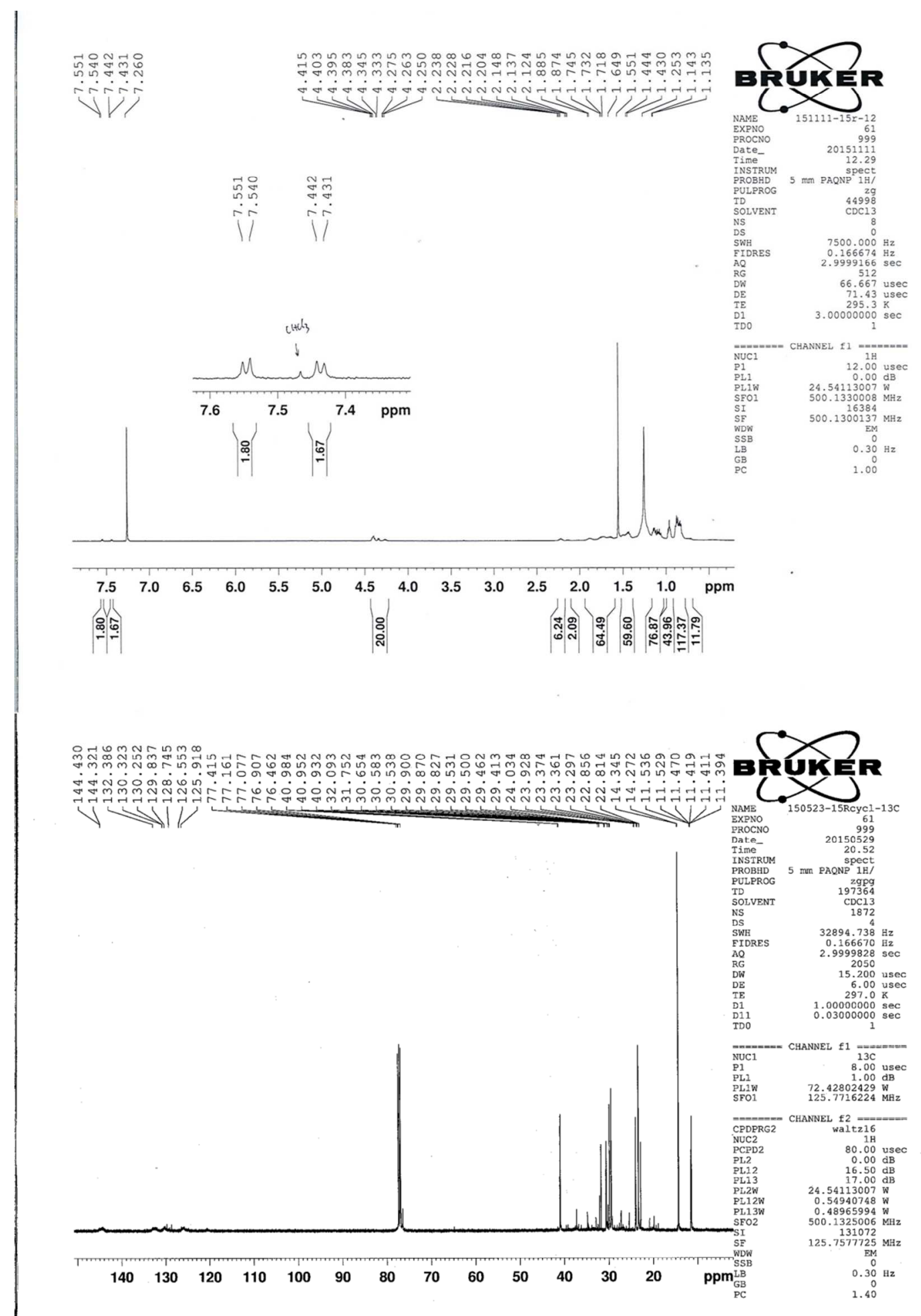

Figure S1 $1{ }^{1} \mathrm{H}$ and ${ }^{13} \mathrm{C}$ NMR spectra of FBT-15R 

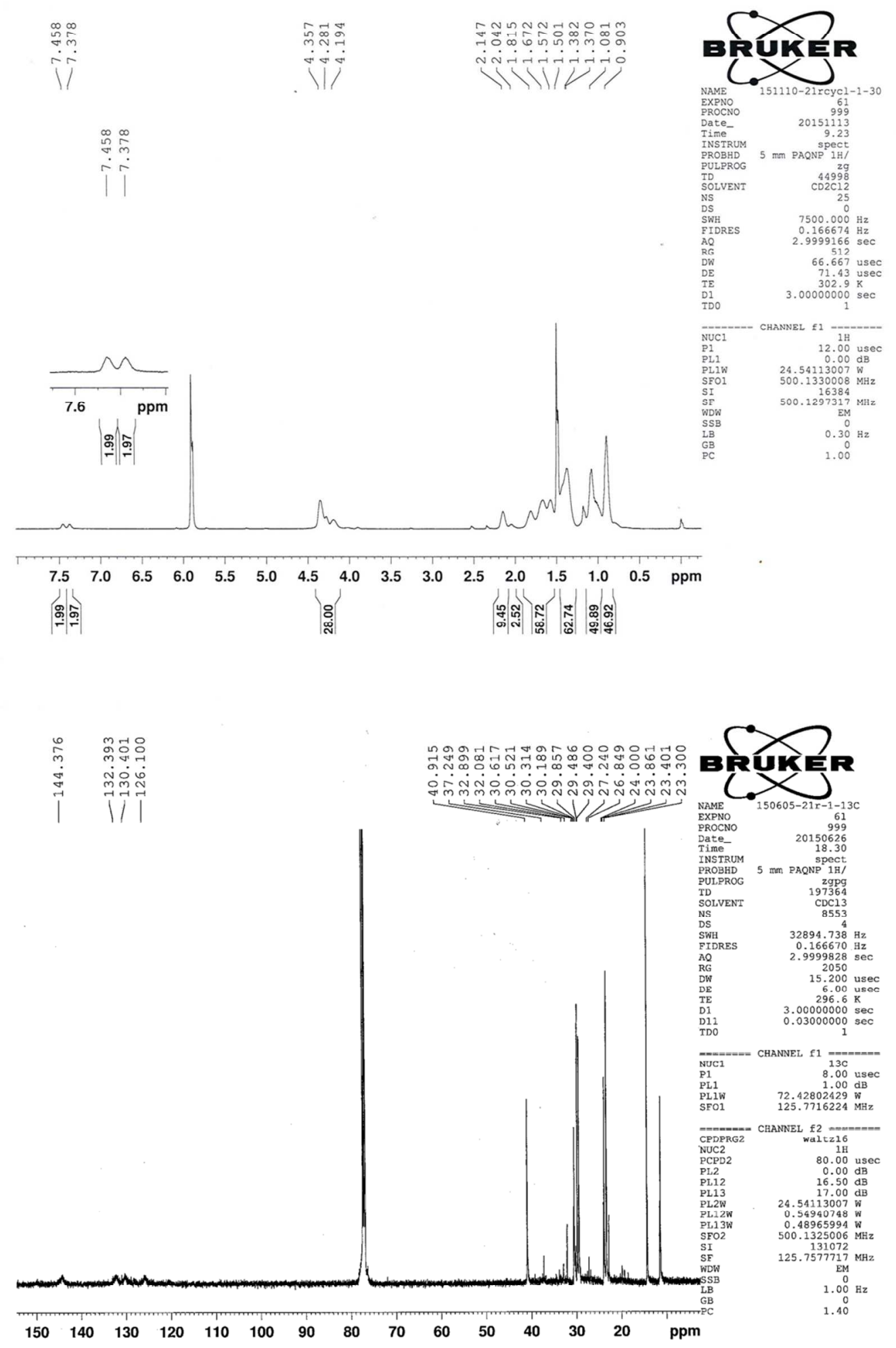

Figure S12 ${ }^{1} \mathrm{H}$ and ${ }^{13} \mathrm{C}$ NMR spectra of FBT-21R 


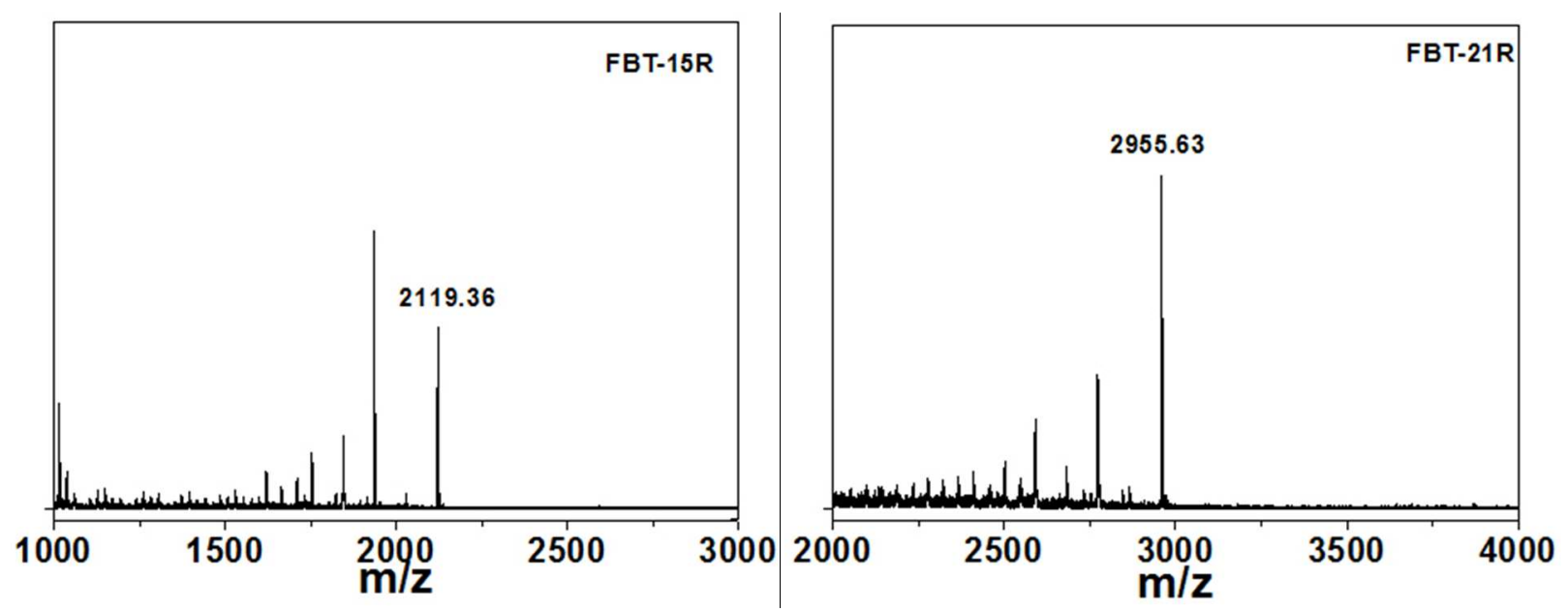

Figure S13 MALDI-TOF MS spectra of FBT-15R and FBT-21R. 